\title{
PREPOSISI "di" DALAM PERSPEKTIF SEMANTIK KOGNITIF
}

\author{
Zaqiatul Mardiah \\ Fakultas Ilmu Pengetahuan Budaya, Universitas Al-Azhar Indonesia \\ Pos-el: zaqiah@uai.ac.id
}

\begin{abstract}
Abstrak
KBBI daring menyebut $d i$ sebagai kata depan yang menandai tempat, waktu, dan dapat pula semakna dengan preposisi akan, kepada, dari. Dengan perspektif semantik kognitif, makna di tidak hanya terbatas pada lima hal yang disebut dalam KBBI tersebut. Penelitian ini mengamati penggunaan preposisi di dengan mengandalkan paradigma semantik kognitif Tyler dan Evans (2003) dan data bahasa Indonesia dari leipzig corpora (https://corpora.uni-leipzig.de/en?corpusId=ind_mixed_2013). Hasil pengamatan menyatakan bahwa preposisi di digunakan dengan makna yang lebih luas dari lima hal yang disebutkan KBBI daring, yaitu makna lokatif (spasial dan nonspasial), makna berada pada lingkup sesuatu, makna beban, makna temporal, dan makna menggantung pada. Makna-makna itu sejatinya bermuara pada satu makna primer, yaitu makna membatasi ruang baik secara fisik geometris, maupun nonfisik geometris.

Kata kunci: preposisi, makna primer, makna perluasan, semanti kognitif, spasial
\end{abstract}

\begin{abstract}
The online KBBI mentions di as a preposition that marks the place, and time. It also has the same meaning with the prepositions kepada, akan, dan dari. Using a cognitive semantic perspective, the meaning of di is not only limited to the five things mentioned in the online KBBI. This study observes the use of the preposition di by relying on the cognitive semantic paradigm of Tyler and Evans (2003) and Indonesian data from leipzig corpora (https://corpora.uni-leipzig.delen?corpusId=ind_mixed_2013). The results state that the preposition di is used with a broader meaning than the five things mentioned in the online KBBI. Those extended senses are locative sense (spatial and non-spatial), being in the scope of something sense, burden sense, temporal sense, and hanging on sense, which actually lead to one primary sense, that is the containment sense, both spatial physico-geometric and non-spatial physico-geometric.
\end{abstract}

Keywords: preposition, primary sense, extended sense, cognitive semantics, spatial 


\section{PENDAHULUAN}

KBBI menyajikan empat poin penjelasan pada lema di, yaitu (1) kata depan untuk menandai tempat, (2) kata depan untuk menandai waktu, (3) semakna dengan akan dan kepada, dan (4) semakna dengan dari. Keempat poin itu diberi tanda $\mathrm{p}$ yang merupakan akronim dari preposisi (https://kbbi.kemdikbud.go.id/entri/di).

Sebagai sebuah preposisi, $d i$ merupakan function word yang tidak dapat mengalami derivasi. di menempati kelas kata tertutup yang bertugas menjadi perangkai sebuah kata dengan kata lain membentuk frase eksosentris di dalam kalimat (Moeliono dkk, 2017: 375). Secara semantik, tugasnya adalah menandai berbagai hubungan makna antara konstituen di depan preposisi dan konstituen di belakangnya. Dalam kalimat Adik menangis di kamar, misalnya, preposisi $d i$ menyatakan makna lokatif yang menghubungkan perbuatan menangis dengan kamar (yang menjadi tempat adik menangis).

Begitu pula pada kalimat Hewan itu lahir di jaman purbakala, di menyatakan makna temporal tentang waktu lahirnya hewan. Makna lokatif dan makna temporal adalah dua makna yang paling banyak ditemukan dalam penggunaan preposisi di. Sekalipun demikian, pada pemakaian yang lebih luas yang dapat dilihat dalam korpus linguistik, preposisi di dapat menyatakan beragam makna; dan itu melampaui makna lokatif dan makna temporal. Bahkan tiga preposisi yang disebut KBBI semakna dengan preposisi $d i$, ternyata belum sepenuhnya digunakan penutur bahasa Indonesia untuk keperluan makna itu.

Kajian makna preposisi sebagai sebuah partikel spasial memang lebih banyak memanfaatkan ancangan linguistik kognitif. Linguistik kognitif memberi perhatian pada hubungan antara pengetahuan bahasa dengan pengetahuan dunia rill. Dalam sejumlah literatur linguistik kognitif dijelaskan bahwa berbahasa bukan hanya dimaknai dari hubungan kata dengan kata lain dalam konstruksi kalimat. Makna sebuah kata ada di kepala manusia sebagai hasil proses persepsi yang berulang, yang kemudian dihubungkan dengan kenyataan dan membentuk struktur konseptual tentang kata itu (Mardiah, 2019).

Ada sejumlah studi tentang preposisi dalam bahasa Inggris yang mengandalkan linguistik kognitif, misalnya, karya dari Ferrando (1998) tentang preposisi on, in, at. Ferrando 
menggunakan pendekatan semantik kognitif Langacker (1987, 1991a, 1991b) dan Lakoff (1987, 1988) yang mengusung beberapa gagasan, yaitu experentialism, categorisation based on prototype, family resemblances, image schema, and polysemy model for preposition. Karya lain Ferrando (2011) adalah studi tentang preposisi behind, yang juga merujuk pada semantik kognitif Langacker (1987) tentang hierarchical network, Lakoff and Brugman (1987) tentang radial network, dan Deane (1993) tentang multidimensional structures.

Yang juga menarik perhatian dalam dekade yang cukup panjang adalah studi tentang over dalam bahasa Inggris. Kajian over menuai perdebatan yang dimulai dari tesis magister Brugman di tahun 1981. Paradigma radial network yang disajikan Brugman dalam menganalisis makna over, dianggap tidak memadai oleh Langacker (1987). Menurut Langacker, sejumlah makna yang muncul dari penggunaan over, tidak begitu saja "memancar" secara sporadis dari makna intinya. Ada hierarki makna yang dapat ditelusuri sehingga jelas tingkatannya. Karena itulah, Langacker menawarkan hierarchical network untuk menggambarkan makna-makna dari berbagai penggunaan over. Hierarki makna itu dapat diperoleh dari sejumlah penggunaan over dalam kalimat. Ada kalimat yang benar-benar merepsentasi makna spasial over secara fisik-geometris. Ada pula kalimat yang menggunakan over tidak dalam bingkai spasial fisik geometris. Akan tetapi, semua makna yang muncul dalam kalimat-kalimat itu tidak pernah keluar dari makna asalnya yang menjadi inti makna. Itulah struktural konseptual tentang makna over itu yang tersimpan dalam memori penuturnya.

Ada yang perlu dicermati dari penelitian-penelitian tentang preposisi bahasa Inggris itu, yaitu unsur subjektifitas dan mana suka yang mengandalkan intuisi dalam menentukan makna preposisi. Tahun 2003, Tyler dan Evans melanjutkan penelitian terhadap preposisi bahasa Inggris yang tetap memanfaatkan ancangan semantik kognitif. Mereka mencoba menyempurnakan metodologi dalam mencermati aspek semantik kognitif dalam penggunaan preposisi dalam bahasa Inggris. Unsur subjektifitas dan mana suka dalam menentukan makna primer sebuah preposisi spasial sangat dihindari oleh Tyler Evans. Karena itulah mereka menawarkan model disebut dengan PPM, yaitu principled polysemy model 'model polisemi berprinsip. 
PPM (principled polysemy model) atau model polisemi berprinsip adalah ancangan yang berfokus pada gagasan utama semantik kognitif, yaitu bahwa makna itu sejatinya adalah konseptual (Tyler and Evans, 2003: 18). Kata konseptual ini merujuk pada struktur berpikir manusia ketika mempersepsi sesuatu, yang terjadi secara berulang dalam aktifitas keseharian. Proses yang berulang ketika mempersepsi sebuah situasi menjadi input atau masukan dalam kognisi manusia. Pada saat itulah manusia mencoba memetakan, mengklasifikasikan, dan mengkategorisasikan setiap masukan yang merupakan hasil dari proses perseptual. Semua terjadi begitu saja, secara otomatis dan tanpa disadari dalam kognisi manusia (Navarro, 1998: 59).

Manusia menyusun struktur konseptualnya dalam kognisinya berdasar pada input dari proses persepsi yang berulang. Situasi yang mereka alami dalam proses persepsi adalah bagian dari embodiment experience yang melekat dalam benak mereka yang membentuk struktur konseptual (Rohrer, 2007). Setiap situasi yang diungkapkan manusia dengan bahasanya, secara otomatis sudah pasti telah melalui proses persepsi dan konsepsi yang sistematis. Memori dalam kognisinya menyimpan setiap situasi itu, memilah-milahnya, mengelompokkannya menurut kriteria yang ia ciptakan sendiri di benaknya, mengikuti kenyataan yang dipersepsi. Pada kondisi itu, sebenarnya manusia telah membuat kategorisasi. Mereka membuat sekat-sekat untuk situasi atau objek yang memiliki kesamaan ciri dan karakteristik. Struktur konseptual itu tersusun dengan baik karena fungsi kognisi bekerja mengkategorisasi secara otomatis setiap input yang dipersepsi.

Dalam konteks penggunaan preposisi, pada hakikatnya manusia selalu mempelajari situasi dan peristiwa yang ada di sekelilingnya untuk menyatakan bahasanya, yang antara lain menggunakan preposisi. Sejak manusia lahir, ia telah menyerap pola-pola penggunaan preposisi itu, sehingga ia dapat menggunakan preposisi itu jika situasi yang menjadi syarat untuk menyatakannya terpenuhi. Syarat yang dimaksud tersebut adalah semacam karakteristik umum yang "perlu ada" dan "yang mencukupi" (dalam filsafat pengetahuan Aristoteles) untuk terpenuhinya situasi yang menggunakan preposisi itu. Karakteristik umum yang perlu ada itu dalam istilah Rosch (1975) disebut dengan prototipe. Prototipe adalah sebuah makna asal yang memuat inti makna dengan ciri-ciri wajib, yang selalu ada dalam setiap situasi atau objek, sekalipun ciri lainnya yang berbeda juga 
hadir bersamaan dengan makna inti itu. Ciri pembeda itulah yang membuat makna itu menjadi meluas, namun tetap memuat makna inti itu. Dalam istilah Tyler dan Evans (2003), prototipe adalah protoscene yang menjadi makna primer (primary sense) atau makna asli dari sebuah leksem, sedangkan makna pembedanya, mereka sebut makna perluasan (extended sense).

Untuk menentukan makna primer sebuah preposisi, menurut Tyler dan Evans (2003) ada 5 hal yang perlu dipenuhi, yaitu 1) makna awal yang sudah teruji; 2) unggul dalam jejaring semantik; 3) relasinya dengan preposisi lain; 4) prediksi gramatikal; dan 5) unit-unit komposisinya. Adapun untuk menentukan makna perluasannya, Tyler dan Evans (2003: 42-44) menyebut dua kriteria, yaitu 1) makna tambahan atau makna pembeda yang muncul sebagai akibat dari penggunaan pada situasi yang berbeda, dan itu tidak didapati pada yang lainnya, dan 2) makna perluasan juga harus bebas konteks.

Mengacu pada Model Polisemi Berprinsip (PPM) dari Tyler dan Evans (2003), penelitian ini berusaha mengungkap makna-makna preposisi $d i$ yang berbasis pada ancangan semantik kognitif dan data dari korpus linguistik.
Sesuai dengan nama model yang ditawarkan Tyler dan Evans (2003), kajian ini berasumsi bahwa preposisi $d i$ bersifat polisemis. Dengan asumsi itu, penelitian ini akan menemukan makna primer dan sejumlah makna perluasan preposisi $d i$.

\section{METODE PENELITIAN}

Penelitian ini dipandu oleh ancangan semantik kognitif Tyler dan Evans (2003) yang berasumsi bahwa setiap kata berpotensi menjadi polisemi. Karena itulah model yang disajikan adalah model polisemi berprinsip atau PPM (principled polysemy model). Model ini memiliki 5 kriteria dalam menentukan makna primer sebuah preposisi, dan 2 kriteria untuk menentukan makna perluasannya.

Ancangan linguistik kognitif yang berbasis pada linguistik korpus sangat dianjurkan, karena menurut Hunston dan Francais (2000: 15), investigasi bahasa akan menyajikan hasil yang andal apabila menggunakan data dalam jumlah besar yang natural, yang selalu mutakhir dan tersusun dalam sistem elektronik dengan perangkat lunak tertentu, sehingga memudahkan dalam memilih dan memilah, dalam menghitung frekuensi, dan lain-lain. Mengacu pada Hunston dan 
Preposisi di dalam Perspektif Semantik Kognitif...

Francais (2000: 15), kevalidan dan keandalan hasil penelitian ini akan terealisir dengan memanfaatkan kemutakhiran data, kealamiahannya, dan keaktualannya dari linguistik korpus. Karena itulah, data dalam penelitian ini diambil dari korpus linguistik bahasa Indonesia dari Leipzig Corpora ((https://corpora.uni-

leipzig.de/en?corpusId=ind_mixed_2013) dan diri penulis sebagai penutur jati bahasa Indonesia. Data yang diambil berupa konstruksi kalimat yang memuat preposisi di. Ada 19.146.660 konstruksi yang memuat preposisi $d i$ dalam situs tersebut, yang diambil pada tahun 2013 dari semua sumber. Dalam penelitian ini, kami mengambil 1000 konstruksi teratas yang memuat preposisi $d i$.

Kalimat atau konstruksi yang memuat preposisi $d i$ dari korpus tersebut dikelompokkan berdasarkan jenis objek atau entitas yang direlasikan. Proses pengelompokan itu melibatkan teori tentang trajector dan landmark (Langacker, 1987). Objek yang berada sebelum preposisi di adalah trajector, sedangkan lokasi atau entitas yang menjadi rujukan trajector adalah landmark, yang posisinya berada setelah preposisi di. Preposisi di yang merelasikan trajector dan landmark yang berupa objek konkret disebut menyatakan relasi spasial. Sementara preposisi $d i$ yang merelasikan trajector dan landmark yang salah satu atau keduanya berupa objek abstrak seperti keadaan, tindakan, dan proses dapat disebut menyatakan relasi nonspasial.

Secara umum, riset ini menggunakan metode penelitian kualitatif deskriptif, yang menyajikan mekanisme pemaknaan yang dilakukan kognisi manusia Indonesia sebagai penutur bahasa Indonesia terhadap penggunaan leksem spasial, khususnya preposisi $d i$.

\section{HASIL DAN PEMBAHASAN}

$d i$ adalah preposisi yang menghubungkan trajector (TR) dan landmark (LM) baik secara fisik geometris, maupun sebaliknya. Artinya, trajector yang dihubungkan oleh preposisi $d i$ dapat berupa objek konkret, dan dapat pula berupa objek abstrak. Begitu pula dengan landmark-nya. Berikut adalah data yang memperlihatkan penggunaan preposisi di dengan TR yang berupa kegiatan dan LM yang berupa objek fisik yang konkret.

(1) Ibu dan Ayah menangis di sampingku

(innddrryy.wordpress.com)

(2) Kuajak dia untuk makan di 
warung tenda saja (kisahdewasa35.wordpress.com).

(3) Selain itu di dinding kamar pun dimanfaatkan untuk storage dengan menggunakan ambalan (sirine.uns.ac.id).

Tiga kalimat itu menyatakan makna di sebagai preposisi yang menandai tempat atau lokasi. Peritiwa menangis (1) terjadi pada lokasi di samping aku, peristiwa makan (2) berlangsung pada lokasi warung tenda, dan storage (3) ditempatkan pada lokasi dinding kamar. Jika dicermati lebih tajam, ada perbedaan mendasar dari setiap penggunaan di dalam 3 data itu. Namun, setiap makna mengerucut pada satu muatan makna inti. Mengacu pada 5 kriteria Tyler dan Evans (2003), penelitian kecil mencoba menemukan muatan makna inti preposisi di yang sudah tersimpan dalam memori penutur bahasa Indonesia.

\section{A. Makna Primer Preposisi di}

Ada 5 kriteria untuk menentukan makna primer sebuah preposisi, yaitu 1) makna yang sejak awal sudah teruji secara historis; 2) makna yang unggul dalam jejaring semantik; 3) makna yang memiliki relasi dengan preposisi lain; 4) makna yang diperoleh dengan prediksi gramatikal; dan 5) makna yang diperoleh ketika preposisi digabung dengan unitunit komposisinya (Tyler and Evans, 2003).

Untuk kriteria pertama, pada sejumlah literatur-literatur awal yang menyajikan preposisi bahasa Indonesia, preposisi $d i$ dijelaskan sebagai penanda hubungan tempat (Ramlan, 1980; Kridalaksana, 1986; Effendi \& Aritonang, 1993: 43; Moeliono dkk, 2017 , 374-376;

https://kbbi.kemdikbud.go.id/entri/di).

Penjelasan tersebut memberikan gambaran bahwa preposisi $d i$ merelasikan objek-objek yang bersifat spasial fisik geometris. Relasinya bersifat mewadahi, yakni LM menjadi wadah bagi TR, seperti yang ada pada data (1)(3). Karena itulah sejumlah literatur itu menyebutnya penanda hubungan tempat, atau sebagai kata depan yang menandai tempat. Tidak ada penjelasan tambahan dalam literatur itu, bagaimana dan apa yang dimaksud dengan tempat itu, sehingga maknanya dapat melingkupi semua hal yang dapat dimaknai sebagai sebuah wadah atau lokasi yang menaungi atau membatasi ruang gerak dari TR.

Mengikuti kriteria kedua, dari 1000 konstruksi teratas dalam data 
Leipzig corpora, $80 \%$ menunjukkan makna yang menandai hubungan lokasi atau tempat, baik yang bersifat konkret maupun abstrak. Perhatikan data berikut!

(4) Dalam kesendirian di sudut jendela. (hendrisangpenyair.blogspot.com.

(5) Mereka berjanji untuk terus berinvestasi di pasar modal Indonesia (ns1.kompas.web.id).

(6) Malware ini melakukan perubahan DNS saat pengguna browsing di internet (takdikenal.blogspot.com). di sudut jendela pada

memperlihatkan posisi seseorang yang berada pada lokasi pojok dekat jendela, karena sudut jendela hakikatnya tidak dapat menjadi wadah atau tempat bagi seseorang. Posisi sudut jendela yang sudah pasti sempit, tidak memungkinkan bagi seseorang untuk berdiri atau duduk, apalagi berbaring di situ. Di pasar modal (5) dan di internet (6) menunjukkan wadah yang bersifat non spasial fisik geometris. Pasar dan internet bukanlah tempat yang bersifat fisik, karena wujudnya tidak dapat dilihat, tapi dapat diindera.

Pada kriteria ketiga, preposisi $d i$ berelasi makna dengan preposisi pada, seperti yang dinyatakan dalam KBBI. Itu berarti $d i$ bersinonim dengan pada. Dua preposisi itu menandai hubungan yang menempatkan TR pada lokasi LM.
Kesinoniman ini memperkuat argumen bahwa preposisi $d i$ memang dimaknai sebagai sebuah relator yang menghubungkan sebuah entitas berada pada entitas lain dengan wujud yang beragam. Dalam bahasa yang sederhana, preposisi di menjembatani hubungan sebuah objek (TR) yang menempati objek lain (LM). Dengan kata lain, LM menjadi wadah bagi TR.

Kriteria keempat memberikan isyarat bahwa makna preposisi $d i$ dapat dicermati dari prediksi gramatikal. Untuk menentukan makna asli dari preposisi $d i$, dapat dilakukan dengan memprediksi makna lain dari kalimat yang memuat preposisi di. Makna lain yang dimaksud disini adalah makna yang bukan mengisyaratkan mewadahi, tetapi tetap memperlihatkan unsur-unsur berada pada posisi, situasi, atau lokasi. Misalnya:

(7) Sentimen kedua partai politik tersebut ternyata hanya sebatas di petingginya saja. (www.balipost.co.id).

(8) Ia perhatikan ada sebuah lampu di langit-langit, tapi ia tidak tahu cara menyalakannya. (bible.org)

(9)

Betapa agungnya nilai seorang ibu itu di sisi Allah. (zai6973.blogspot.com) 
keheningan, di ufuk timur),

Data (7) menunjukkan bahwa sentimen partai (TR) berada pada wadah yang disebut petinggi partai (LM). Petinggi partai tentu saja bukan wujud fisik yang dapat menjadi lokasi bagi sebuah objek. Namun, preposisi di dalam konstruksi itu masih memperlihatkan "sesuatu yang membatasi", yaitu hanya pada petinggi saja, tidak kepada yang lain. Unsur lokatif atau sebagai wadah (LM), hakikatnya menjadi pembatas bagi objek (TR) yang diberinya tempat atau wadah itu. Penjelasan ini juga berlaku untuk data (9). Adapun data (8) tetap menunjukkan hubungan tempat yang bersifat spasial fisik geometris, namun menunjukkan posisi yang menggantung. Ada nuansa makna yang berbeda, yaitu posisi wadah atau tempat yang biasanya di bawah TR, tetapi pada (8) LM berada di atas TR. Sekalipun demikian, makna lokatif masih dirasakan dalam kalimat itu.

Kriteria kelima memandu penentuan makna primer preposisi $d i$ dengan melihat pada unit-unit yang bergabung dnegan preposisi di. Satuan leksikal yang mendampingi preposisi $d i$ (sebelum dan sesudah di) dapat berupa:

a. nomina atau frase nominal ( $d i$ atas, di kamar, di siang hari, di b. Verba yang bersanding sebelum preposisi $d i$ tidak membentuk kolokasi tetap seperti preposisi pada (Mardiah, 2019). Semua verba sesuai konteksnya dapat disandingkan dengan preposisi $d i$.

c. pronomina (di aku, di kamu),

d. nomina lokatif dan nama diri (di sekolah itu, di pasar, di restoran dan di Andi, di Rina, di Santoso). Kata-kata yang menyandingi preposisi $d i$ baik sebelumnya maupun setelahnya akan mempengaruhi makna peposisi di tersebut. Akan tetapi, sebagai sebuah struktur konseptual yang sudah ajeg di dalam kognisi manusia, makna asli yang menjadi muatan inti dari preposisi di akan selalu terepresentasi dalam setiap penggunaan di. Sekalipun dapat dipastikan ada beragam makna tambahan yang muncul dalam penggunaan itu.

Setelah lima kriteria dipenuhi, protoscene yang merupakan skema citra dalam benak penutur bahasa Indonesia dapat diilustrasikan. Berikut ini adalah skema citra dari makna asli preposisi $d i$ yang memperlihatkan makna mewadahi atau menempatkan sesuatu pada sesuatu baik spasial fisik geometris, maupun non spasial fisik geometris. Konsekuansi dari 
situasi mewadahi atau menempatkan itu adalah ada aspek LM yang membatasi ruang gerak $\mathrm{TR}$, atau memproteksi TR dari unsur-unsur di luar LM.

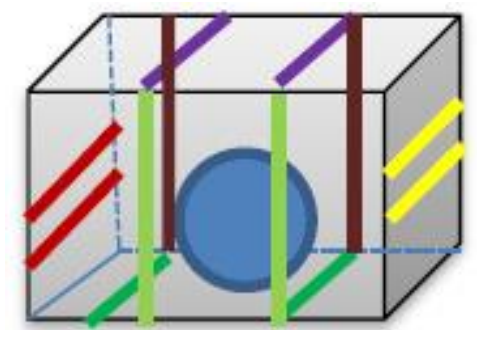

Gambar 1: Protoscene makna primer preposisi di

Ada dua objek dalam gambar 1, yaitu benda bulat warna biru (TR) dan kubus (LM). Bentuk bulat dan warna biru tidak bermakna apa-apa; hanya untuk membedakan dari bentuk kubus dan warna lainnya. Preposisi di merelasikan benda bulat (TR) pada posisi dalam kubus (LM). Ada 8 sisi kubus yang diberi warna berbeda. Warna-warna itu untuk membedakan setiap sisi, yaitu

- warna kuning adalah sisi kanan

- warna merah adalah sisi kiri

- warna coklat adalah sisi belakang

- warna hijau muda adalah sisi depan

- warna ungu adalah sisi atas

- warna hijau tua adalah sisi bawah.

Situasi dalam gambar 1 menunjukkan:

- pada umumnya ukuran TR seringkali lebih kecil dari LM

- posisi TR dapat dilihat dari berbagai sisi, sehingga dapat dikatakan bahwa TR berada di atas sisi bawah, berada di bawah sisi atas, berada di samping sisi kanan dan kiri, berada di depan atau belakang sisi depan dan belakang

- ketika tujuh sisi kubus dibongkar dan diubah menjadi sejajar dengan sisi bawah, maka TR tetap menempati posisi yang sama. Hal itu berarti setiap sisi dari kubus itu dapat berubah mengikuti konteks, namun posisi TR tidak berubah.

\section{B. Makna Perluasan Preposisi $d i$}

Ada dua kriteria yang dijelaskan Tyler dan Evans (2003: 42-44) dalam menentukan makna perluasan preposisi $d i$, yaitu (1) makna tambahan atau makna pembeda yang muncul sebagai akibat dari penggunaan pada situasi yang berbeda, dan itu tidak didapati pada yang lainnya, dan 2) bebas konteks.

Berdasarkan sampel data, ditemukan makna tambahan atau makna pembeda preposisi $d i$ yang menjadi extended senses, yaitu: 
Makna lokatif: di dalam, di atas, di bawah, di samping, di tengah, di antara.

(10) Pendekatan simulasi yang diajukan diilustrasikan dalam gambar di atas.

(11) Inilah sinergi yang manis dalam rumah,biduk kecil di tengah samudra (good.abatasa.com).

Makna lokatif yang dimaksud di sini adalah makna yang muncul dalam penggunaan $d i$ yang menandai hubungan tempat. Apabila merujuk pada gambar 1, makna-makna itu dapat dirinci lebih detail menjadi makna di atas, di bawah, di samping, di tengah, di antara, di depan, di belakang, mengikuti posisi TR dalam LM pada gambar 1 yang dapat dilihat dari berbagai sudut pandang. Kontruksi (10) dan (11) adalah di antara yang memperlihatkan makna itu. Makna ini disebut makna perluasan, karena ada makna tambahan yang membuat penggunaan preposisi di menjadi berbeda satu sama lain. Selain itu, makna pembeda dalam (10) dan (11) dilepaskan dari konteksnya, sehingga dimaknai apa adanya dari kalimat itu.

Makna berada dalam lingkup sesuatu atau dalam cakupan sesuatu yang nonspasial fisik geometris
(12) Wanita anggun dengan make up tebal ini bak seorang merak di mata Yuda. (yes24.co.id).

(13) Kau selalu di hatiku.

(14) Isabella dan Sofia lahir di keluarga dengan tradisi memasak yang kuat (mirror2.polsri.ac.id).

Kalimat (12) menggambarkan bahwa wanita anggun itu dalam lingkup jangkauan pandangan Yuda. Begitu pula dengan di hatiku dalam kalimat (13), yang menunjukkan bahwa engkau berada dalam lingkup perasaanku. Tidak berbeda dengan frase di keluarga dalam (14) yang mengisyaratkan makna dalam lingkup sebuah keluarga yang hobi memasak.

Makna ini tentu saja selaras dengan makna primer. Sesuatu (TR) yang berada pada posisi di dalam sesuatu yang lain (LM) sudah dapat dipastikan berada dalam lingkup sesuatu yang lain itu (LM). Artinya, TR dibatasi dan diproteksi oleh batas-batas LM, yang dalam 3 kalimat itu tidak berwujud fisik geometris. Namun, ada makna pembeda di situ, yaitu sifat non spasial dan non fisik entitas LM. Kriteria bebas konteks pada makna perluasan ini, sejatinya telah dilanggar oleh Tyler dan Evans. Ketika mereka menjelaskan makna over dalam kalimat The cat jumps over the wall (2003: 9-11), makna perluasana $A-B-C$ trajectory itu muncul dari konteks kalimat yang 
memperlihatkan sanding kata jumps dan over.

\section{Makna temporal}

Makna temporal disebut dalam KBBI sebagai salah satu tugas preposisi di, yakni menandai hubungan waktu. Kalimat-kalimat di bawah ini menunjukkan penggunaan di yang merelasikan sebuah peristiwa atau keadaan, atau situasi (TR) pada garis waktu (LM). Yang menjadi wadah adalah garis waktu.

(15) Karena tidak harus melalui sekolah yang berbungkus RSBI anak dapat sukses di era global. (www.lampungpost.com).

(16) Tapi kenapa baru sekarang, di saat tengah disoroti ada masalah hukum? (forum.otomotifnet.com).

(17) Pemandangan kota Bali di malam hari yang cantik menyambut para peserta setibanya di GWK. (lpse.badungkab.go.id) di era global pada (15) dan di malam hari pada (17) memperlihatkan LM dalam wujud garis waktu yang memanjang, yaitu era global dan waktu malam. Era global itu adalah sebuah durasi tahunan, sedangkan malam hari adalah durasi jam. Makna ini tetap memuat keaslian makna primer, yang memperlihatkan makna membatasi dari segi waktu. di saat tengah disoroti pada
(16) juga menempatkan TR pada waktu yang bersamaan dengan sesuatu yang disoroti. Waktu yang bersamaan itulah yang menjadi garis waktunya.

Makna beban

Makna beban ini merupakan makna yang muncul dari penggunaan preposisi $d i$ yang disandingkan dengan nomina tertentu yang memperlihatkan posisi TR berada di atas LM, sehingga TR menjadi beban bagi LM. Ini menjadi makna pembeda yang merupakan perluasan dari makna primer. Dalam gambar 1, posisi TR di dalam LM berada di atas sisi bawah LM. Dari situasi itu, makna ini tetap merepresentasi makna primer.

(18) Keberhasilan proyek ini ada di pundakmu.

(19) Sebagian wali telah mengkhianati amanah yg ada di pundaknya atas putrinya atau gadisnya. (pulsanew.indonetwork.co.id)

Dua kalimat itu menunjukkan makna beban, yaitu proyek dan amanah (TR) yang berada di atas pundak (LM). TR yang berupa wujud non fisik menjadi beban bagi LM.

Makna pada sisi samping, menempel atau makna menggantung.

Posisi TR terhadap alas LM dalam 
gambar 1 memperlihatkan posisi horizontal relasi atas-bawah. Jika posisi itu diubah vertikal, maka TR akan berada di samping LM. Posisi di samping ini dapat berupa TR menempel pada LM dengan situasi menggantung, dapat pula berupa TR yang hanya berada di samping LM tanpa menempel. Contoh-contoh kalimat di bawah ini, memberikan gambaran bahwa preposisi $d i$ dapat dimaknai sebagai kata yang merelasikan hubungan TR yang menempel dan menggantung pada LM. Bahkan pada (22), situasi yang terlihat adalah TR menggantung pada LM. TR berada pada posisi di bawah LM.

(20) Nama ini pula yang terpampang di tembok atas depan rumah makannya (www.surya.co.id).

(21) Ia menyandarkan punggungnya di dinding rumah tua itu.

(22) Ia perhatikan ada sebuah lampu di langit-langit, tapi ia tidak tahu cara menyalakannya. (bible.org).

(23) Aku melihat foto itu di dinding kamarnya.

Kalimat (20)-(23) juga menjelaskan bahwa preposisi $d i$ bersinonim dengan preposisi pada.

\section{SIMPULAN}

Paradigma semantik kognitif Tyler and Evans (2003) yang digunakan dalam mengkaji makna preposisi $d i$ menyatakan bahwa secara konseptual, preposisi $d i$ memuat makna primer mewadahi atau menempatkan sebuah entitas (TR) pada entitas lain (LM). Makna tersebut tidak hanya mencakup entitas yang berwujud spasial fisik geometris, tapi juga meluas hingga ke entitas yang non spasial dan nonfisik geometris. Makna perluasan yang ditemukan dalam penggunaan preposisi di pada data adalah makna lokatif, makna berada dalam lingkup sesuatu, makna temporal, makna beban, dan makna di samping/menempel/menggantung.

Semua makna perluasan itu tetap merepresentasi muatan inti dalam makna primer, sehingga dapat dikatakan bahwa preposisi di bersifat polisemis dengan makna primer sebagai inti dan makna pembeda sebagai makna perluasan.

\section{DAFTAR PUSTAKA}

Brugman, C. (1981). The story of OVER. MA thesis, University of California: Berkeley.

Effendi, S dan Buha Aritonang. (1993). Preposisi dan Frase Berpreposisi. Jakarta: PPPB Kemendikbud. 
Ferrando, I. N. (1998). A Cognitive Semantics Analysis of the Lexical Unit At, On, and In in English. A Dissertation at Dept. De Filologia Anglesia I Romanica.

Ferrando, I.N. and Birgit Gosser. (2011). Semantic Configuration of the Spatial Concept "Behind" in English, in Journal Studia Universitatis Petru Maior, Philologia. No.10.

Hunston, S \& Francis, G.(2000). Pattern Grammar. A Corpus-driven Approach to the Lexical Grammar of English. Amsterdam/Philadelphia: John Benjamins.

KBBI (https://kbbi.web.id/)

Kridalaksana, Harimurti. (1993). Kelas Kata dalam Bahasa Indonesia. Jakarta: Gramedia.

Lakoff, G. (1987). Women, Fire, and Dangerous Things: What Categories Reveal about The Mind. Chicago: University of Chicago Press.

Lakoff, G. (1988). Cognitive Semantics, in Eco, U. Et al. (eds). Meaning and Mental Representation. Bloomington, Indiana. Indiana: IUP.

Lakoff, G. and C.M. Brugman. (1986). Argument Forms in Lexical Semantics, Berkeley Cognitive Science Report. Berlin: Mouton de Gruyter.

Langacker, Ron. (1987). Foundations of Cognitive Grammar. Vol. 1, Theoretical Prerequisites. Stanford University Press.

Leipzig Corpora (https://corpora.unileipzig.de/en?corpusId=ind_mixed_2 $\underline{013})$
Mardiah, Zaqiatul dan Abdul Mutaali. (2019). Preposisi Spasial pada dalam Tinjauan Semantik Kognitif. Prosiding Seminar Internasional RIKSA BAHASA XIII, Bandung, 23 November 2019 http://proceedings.upi.edu/index.php/ riksabahasa

Moeliono, Anton M., Hans Lapoliwa, Hasan Alwi, Sry Satrya Tjatur Wisnu Sasangka, Sugiyono. 2017. Tata Bahasa Baku Bahasa Indonesia. Edisi 4, Jakarta: BPPB Kemendikbud.

Ramlan. (1980). Kata Depan atau Preposisi dalam Bahasa Indonesia. Yogyakarta: Karyono.

Rohrer, T. (2007). "Embodiment and Experientialisme," dalam The Oxford Handbook of Cognitive Lingusitics. Oxford: OUP.

Rosch, Eleanor. (1975). Cognitive Representation of Semantic categories. Journal of Experimental Psychology: General, 104: 192-233

Tyler, A., \& Evans, V. (2003). The Semantics Of English Prepositions: Spatial Scenes, Embodied Meaning, And Cognition. Cambridge: Cambridge University Press. 